\title{
ANALISIS PERAMALAN JUMLAH PENDUDUK KOTA PALOPO TAHUN 2013 - 2017
}

\author{
Oleh: Muhammad Hajarul Aswad A
}

Dosen Prodi Matematika STAIN Palopo

\begin{abstract}
Abstrak:
Peramalan jumlah penduduk merupakan suatu perhitungan ilmiah yang dapat digunakan untuk keperluan perencanaan dan analisis yang berhubungan dengan kependudukan. Untuk keperluan itu, dipilih metode dengan nilai penyimpangan yang terkecil. Pada artikel ini, terlebih dahulu digunakan tiga metode yaitu Metode Aritmatik, Metode Geometrik, dan Metode Kuadrat Terkecil. Dari ketiga metode ini terlihat bahwa Metode Aritmatik memiliki standar deviasi terkecil sehingga jumlah penduduk Kota Palopo Tahun 2013 - 2017 akan diramalkan dengan menggunakan Metode Aritmatik. Data yang digunakan adalah data sekunder yang diperoleh dari Badan Pusat Statistik Kota Palopo. Dari hasil perhitungan diperoleh jumlah penduduk Kota Palopo untuk tahun 2013 sampai dengan 2017 berturut-turut sebesar 155869 Jiwa, 155869 Jiwa, 162320 Jiwa, 165545 Jiwa, dan 168770, dengan rata-rata pertumbuhan penduduk sebesar 3225 Jiwa per tahun atau sekitar 2,25\%.
\end{abstract}

Kata Kunci: Metode Aritmatik, Metode Geometrik, dan Metode Kuadrat Terkecil

\section{Pendahuluan}

A. Keadaan Geografis dan Kependudukan Kota Palopo

Geografis Kota Palopo, yang berjarak kurang lebih 375 Km sebelah Utara dari Kota Makassar, terletak pada 2 ${ }^{\circ} 53^{\prime} 15^{\prime \prime}$ -

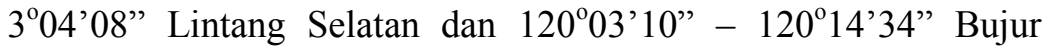
Timur. Kota Palopo berbatasan langsung dengan Kecamatan Wakenrang Kabupaten Luwu di sebelah Utara, Teluk Bone di sebelah Timur, sebelah Selatan dengan Kecamatan Bua Kabupaten Luwu, dan Kecamatan Tondon Nanggala Kabupaten Tana Toraja di sebelah Barat. Luas wilayah administrasi Kota Palopo sekitar 247,52 kilometer persegi atau setara dengan kurang lebih 0,39\% luas wilayah Propinsi Sulawesi Selatan. Secara administratif Kota Palopo terbagi menjadi 9 kecamatan dan 48 kelurahan, dengan sekitar $62 \%$ wilayahnya berupa dataran rendah dengan ketinggian 
0 - $500 \mathrm{~m}$ diatas permukaan laut, dan hanya sekitar $14 \%$ berupa dataran tinggi dengan ketinggian diatas $1000 \mathrm{~m}$ di atas permukaan laut, selebihnya terletak di antara $501-1000 \mathrm{~m}$ di atas permukaan laut.

Penduduk adalah semua orang yang berdomisili di wilayah geografis Republik Indonesia selama enam bulan atau lebih dan mereka yang berdomisili kurang dari enam bulan tetapi bertujuan untuk menetap. Penduduk suatu wilayah merupakan orang yang tinggal di wilayah tersebut, dan atau orang yang secara hukum berhak tinggal di daerah tersebut berdasarkan kepemilikan surat resmi berupa bukti kewarganegaraan atau sejenisnya.

Penduduk Kota Palopo pada akhir tahun 2011 tercatat sebanyak 149.419 jiwa. Pada umumnya jumlah penduduk tersebar tidak merata di setiap kecamatan, dan dari sembilan kecamatan terdapat dua kecamatan yang jumlah penduduknya terbilang sangat padat yaitu Kecamatan Wara (31.335 jiwa) dan Kecamatan Wara Timur (31.308 jiwa). Sementara Kecamatan Sendana adalah kecamatan dengan jumlah penduduk terkecil yakni 5.790 jiwa.

Pola penyebaran penduduk Kota Palopo jika dibandingkan dengan luas wilayah yang dihuni cukup timpang. Misalnya saja Kecamatan Wara dengan jumlah penduduk 31.335 jiwa hanya memiliki luas $11,49 \mathrm{Km}^{2}$, sementara Kecamatan Sendana dengan jumlah penduduk 5.790 jiwa memiliki luas $37,09 \mathrm{Km}^{2}$ atau hampir 3 kali luasnya dari Kecamatan Wara.

Tabel 1. Luas Wilayah, Jumlah Penduduk, dan Kepadatan Penduduk Menurut Kecamatan Tahun 2011.

\begin{tabular}{|c|l|c|c|c|}
\hline No & Kecamatan & $\begin{array}{c}\text { Luas Wilayah } \\
\left(\mathbf{K m}^{\mathbf{2}}\right)\end{array}$ & $\begin{array}{c}\text { Jumlah Penduduk } \\
\text { (Jiwa) }\end{array}$ & $\begin{array}{c}\text { Kepadatan Penduduk } \\
\left(\mathbf{J i w a} / \mathbf{K m}^{\mathbf{2}}\right)\end{array}$ \\
\hline 1 & Wara Selatan & 10,66 & 10226 & 959,29 \\
\hline 2 & Sendana & 37,09 & 5790 & 156,11 \\
\hline 3 & Wara & 11,49 & 31335 & 2727,15 \\
\hline 4 & Wara Timur & 12,08 & 31308 & 2591,72 \\
\hline 5 & Mungkajang & 53,8 & 7052 & 131,08 \\
\hline 6 & Wara Utara & 10,58 & 19203 & 1815,03 \\
\hline 7 & Bara & 23,35 & 23190 & 993,15 \\
\hline 8 & Tellu Wanua & 34,34 & 11819 & 344,18 \\
\hline
\end{tabular}




\begin{tabular}{|c|c|c|c|c|}
\hline 9 & Wara Barat & 54,13 & 9496 & 175,43 \\
\hline \multicolumn{2}{|c|}{ Jumlah } & $\mathbf{2 4 7 , 5 2}$ & $\mathbf{1 4 9 4 1 9}$ & $\mathbf{6 0 3 , 6 6}$ \\
\hline
\end{tabular}

Sumber: Palopo Dalam Angka 2012

Jika dilihat berdasarkan jenis kelamin, jumlah penduduk Kota Palopo di tahun 2011 yang berjenis kelamin perempuan lebih besar dibandingkan dengan jumlah penduduk yang berjenis kelamin lakilaki. Penduduk Kota Palopo yang berjenis kelamin perempuan sebanyak 76.170 jiwa sementara yang berjenis kelamin laki-laki sebanyak 73.249 jiwa. Rasio jenis kelamin sebesar 96,17 yang artinya bahwa jika terdapat 100 penduduk Kota Palopo berjenis kelamin perempuan maka ada 96 atau 97 penduduk Kota Palopo yang berjenis kelamin laki-laki. Atau dengan kata lain perbandingan jumlah penduduk Kota Palopo pada Tahun 2011 yang berjenis kalamin perempuan dan laki-laki sudah mendekati 1 banding 1. Perhatikan Grafik 1 berikut:

Grafik 1. Penduduk Kota Palopo tahun 2011 berdasarkan Jenis Kelamin dan Kecamatan

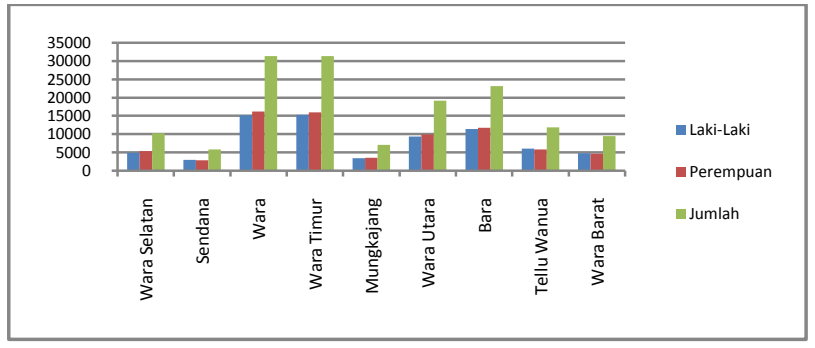

Berdasarkan kelompok usia, dari 149.419 jiwa penduduk Kota Palopo di Tahun 2011 tercatat sekitar 31,09\% berada pada usia muda ( 0 - 14 tahun), 65,20\% berada pada usia produktif ( $15-64$ tahun), dan selebihnya yaitu $3,71 \%$ berada pada kelompok usia tua (65 tahun ke atas).

B. Peramalan (Forecasting)

Peramalan atau forecasting merupakan cara untuk memperkirakan secara kuantitatif apa yang terjadi pada masa 
depan dengan menggunakan data yang relevan pada masa lalu. Keberhasilan dari suatu peramalan sangat ditentukan oleh keakuratan data yang relevan di masa lalu serta ketepatan dalam memilih metode peramalan yang akan digunakan.

Peramalan terhadap jumlah penduduk Kota Palopo jelas merupakan hal penting untuk dilakukan. Karena data penduduk inilah yang seringkali dijadikan dasar untuk perencanaan ataupun sasaran pembangunan di masa yang akan datang. Metode yang digunakan dalam meramalkan jumlah penduduk terus berkembang. Dalam artikel ini diterapkan tiga metode yaitu Metode Arithmatik, Metode Geometrik, dan Metode Least Square.

1) Metode Aritmatik (Stefan Rayer \& Stanley K Smith, 2008: h6)

$$
P_{n}=P_{o}+K a\left(T_{n}-T_{o}\right)
$$

dengan $P_{n}=$ jumlah penduduk pada tahun ke- $n$

$P_{o}=$ jumlah penduduk pada tahun dasar

$T_{n}=$ tahun ke- $n$

$T_{o}=$ tahun dasar

$K a=$ konstanta arithmatik

2) Metode Geometrik (United Nations Publications, 1952: h29)

$P_{n}=P_{o}(1+r)^{n}$

dengan $P_{n}=$ jumlah penduduk pada tahun ke- $n$

$P_{\mathrm{o}}=$ jumlah penduduk pada tahun dasar

$r=$ laju pertumbuhan penduduk

$n=$ jumlah interval

3) Metode Least Square (Rinaldi Munir, 2003: h246)

$\widehat{Y}=a+b X$

dengan

$\hat{Y}=$ jumlah penduduk pada tahun ke- $n$

$X=$ selisih antara tahun ke- $n$ dengan tahun ke-1 yang diketahui $a$ dan $b=$ konstanta

$$
\begin{aligned}
& a=\frac{\left(\sum y\right)\left(\sum x^{2}\right)-\left(\sum x\right)\left(\sum x y\right)}{n \sum x^{2}-\left(\sum x\right)^{2}} \\
& b=\frac{n\left(\sum x y\right)-\left(\sum x\right)\left(\sum y\right)}{n \sum x^{2}-\left(\sum x\right)^{2}}
\end{aligned}
$$


Ketiga metode tersebut terlebih dahulu digunakan untuk menghitung jumlah penduduk Kota Palopo tahun 2006 - 2011 kemudian dilihat metode mana yang hasil perhitungannya memiliki standar defiasi yang kecil terhadap data penduduk Kota Palopo sesungguhnya pada tahun $2006-2011$.

$$
s=\sqrt{\frac{\sum(y-\bar{y})^{2}}{n-1}} \text { (Boediono \& Wayan Koster, 2004; h177) }
$$

Metode yang memiliki standar defiasi terkecil yang akan digunakan untuk meramalkan jumlah penduduk Kota Palopo pada tahun $2013-2017$.

\section{Tujuan}

Artikel ini mencoba meramalkan jumlah penduduk Kota Palopo tahun 2013 sampai dengan 2016 dengan menggunakan data jumlah penduduk Kota Palopo di tahun 2006 sampai dengan 2011. Dari ketiga metode yang digunakan yaitu Metode Arithmatik, Metode Geometrik, dan Metode Least Square, akan dipilih salah satu metode yang memiliki standar defiasi terkecil, yang selanjutnya akan digunakan untuk meramalkan jumlah penduduk Kota Palopo tahun 2013 sampai dengan 2017.

\section{Analisis dan Pembahasan}

Terlebih dahulu akan digunakan Metode Arithmatik, Metode Geometrik, dan Metode Least Square untuk menghitung jumlah penduduk Kota Palopo tahun 2006 sampai dengan tahun 2011 dengan menggunakan data jumlah penduduk di tahun 2011 sebagai tahun dasar.

Terlebih dahulu akan dihitung rata-rata pertambahan penduduk Kota Palopo dari tahun 2006 - 2011. Perhatikan Tabel 2 berikut:

Tabel 2. Rata-Rata Pertambahan Penduduk Kota Palopo Tahun $2006-2011$

\begin{tabular}{|c|c|c|c|}
\hline \multirow{2}{*}{ Tahun } & \multirow{2}{*}{ Jumlah } & \multicolumn{2}{|c|}{ Pertumbuhan Penduduk } \\
\cline { 3 - 4 } & & Jiwa & Persen (\%) \\
\hline
\end{tabular}




\begin{tabular}{|c|c|c|c|}
2006 & 133293 & - & - \\
\hline 2007 & 137595 & 4302 & 3,13 \\
\hline 2008 & 141996 & 4401 & 3,10 \\
\hline 2009 & 146482 & 4486 & 3,06 \\
\hline 2010 & 147677 & 1195 & 0,81 \\
\hline 2011 & 149419 & 1742 & 1,17 \\
\hline Jumlah & $\mathbf{8 5 6 4 6 2}$ & $\mathbf{1 6 1 2 6}$ & $\mathbf{1 1 , 2 6}$ \\
\hline
\end{tabular}

Rata-rata pertambahan penduduk dari tahun 2006 - 2011 adalah

$K_{a}=\frac{P_{11}-P_{06}}{2011-2006}$

$K_{a}=\frac{149419-133293}{2011-2006}=3223,20$ jiwa per tahun

Persentase pertambahan penduduk rata-rata per tahun adalah $r=\frac{11,26}{5}=2,25 \%$

Selanjutnya, bertolak dari data penduduk tahun 2011, akan dihitung kembali jumlah penduduk per tahun dari tahun 2006 sampai dengan tahun 2011 dengan menggunakan ketiga metode sebagaimana yang terlihat pada Persamaan (1), Persamaan (2), dan Persamaan (3).

\section{Metode Arithmatik}

Perhatikan kembali Persamaan (1).

$P_{2006}=P_{2011}+K a(2006-2011)=149419+3225,20(2006-2011)$

$=133293,00$

\section{Metode Geometrik}

Perhatikan Persamaan (2).

$P_{2006}=P_{2011}(1+r)^{2011-2006}=149419(1+0,0225)^{5}=167002,28$

Metode Least Square

Sebelumya perhatikan Tabel 3 berikut:

Tabel 3. Perhitungan Parameter a dan b pada Metode Least Square

\begin{tabular}{|c|c|c|c|c|}
\hline Tahun & Tahun ke(X) & Jumlah (Y) & $\mathbf{X Y}$ & $\mathbf{X}^{\mathbf{2}}$ \\
\hline 2006 & 1 & 133293 & 133293 & 1 \\
\hline 2007 & 2 & 137595 & 275190 & 4 \\
\hline 2008 & 3 & 141996 & 425988 & 9 \\
\hline 2009 & 4 & 146482 & 585928 & 16 \\
\hline 2010 & 5 & 147677 & 738385 & 25 \\
\hline
\end{tabular}




\begin{tabular}{|c|c|c|c|c|}
2011 & 6 & 149419 & 896514 & 36 \\
\hline Jumlah & $\mathbf{2 1}$ & $\mathbf{8 5 6 4 6 2}$ & $\mathbf{3 0 5 5 2 9 8}$ & $\mathbf{9 1}$ \\
\hline
\end{tabular}

Berdasarkan Tabel 3, maka diperoleh nilai parameter $a=$ 131207,47 dan nilai paramater $b=3296,06$. Selanjutnya, berdasarkan Persamaan (3) diperoleh

$Y_{2006}=a+b(2006-2006)=131207,47+3296,06(0)=131207,47$.

Hasil perhitungan jumlah penduduk untuk tahun 2006 sampai dengan 2011 selengkapnya dapat dilihat pada Tabel 4 berikut:

Tabel 4. Jumlah Penduduk Kota Palopo Tahun 2006 - 2011 dengan Menggunakan Metode Arithmatik, Metode Geometrik, dan Metode Least Square

\begin{tabular}{|c|c|c|c|c|}
\hline \multirow[b]{2}{*}{ Tahun } & \multirow{2}{*}{$\begin{array}{c}\text { Jumlah } \\
\text { Penduduk } \\
\text { Sebenarnya } \\
\text { (Jiwa) }\end{array}$} & \multicolumn{3}{|c|}{ Metode } \\
\hline & & Arithmatik & Geometrik & Least Square \\
\hline 2006 & 133293 & 133293,00 & 167002,28 & 131207,47 \\
\hline 2007 & 137595 & 136518,20 & 163327,42 & 134503,52 \\
\hline 2008 & 141996 & 139743,40 & 159733,41 & 137799,58 \\
\hline 2009 & 146482 & 142968,60 & 156218,50 & 141095,64 \\
\hline 2010 & 147677 & 146193,80 & 152780,93 & 144391,70 \\
\hline 2011 & 149419 & 149419,00 & 149419,00 & 147687,75 \\
\hline
\end{tabular}

Selanjutnya, dengan menggunakan Persamaan (6) akan dihitung standar defiasi untuk masing-masing metode. Perhatikan Tabel 5 berikut:

Tabel 5. Standar Deviasi dari Metode Arithmatik,

Metode Geometrik, dan Metode Least Square

\begin{tabular}{|c|c|c|c|c|c|c|c|c|c|c|}
\hline \multirow{3}{*}{ Thn. } & \multirow{3}{*}{$\begin{array}{c}\text { Jumlah } \\
\text { Penduduk } \\
\text { (Jiwa) }\end{array}$} & \multicolumn{9}{|c|}{$\begin{array}{lllllll} & \text { a } & \text { t } & \text { o } & \text { d } & \text { e } \\
\end{array}$} \\
\hline & & \multicolumn{3}{|c|}{ Arithmatik } & \multicolumn{3}{|c|}{ Geometrik } & \multicolumn{3}{|c|}{ Least Square } \\
\hline & & $\begin{array}{c}\text { Peramalan } \\
(\mathbf{Y i})\end{array}$ & $\mathbf{Y}_{\mathbf{i}}-\mathbf{Y}_{\text {mean }}$ & $\left(Y_{i}-Y_{\text {mean }}\right)^{2}$ & $\begin{array}{c}\text { Peramalan } \\
\text { (Yi) }\end{array}$ & $\begin{array}{c}\mathbf{Y}_{\mathbf{i}}- \\
\mathbf{Y}_{\text {mean }}\end{array}$ & $\left(Y_{i}-Y_{\text {mean }}\right)^{2}$ & $\begin{array}{c}\text { Peramalan } \\
\text { (Yi) }\end{array}$ & $\begin{array}{c}\mathbf{Y}_{\mathbf{i}}- \\
\mathbf{Y}_{\text {mean }}\end{array}$ & $\left(\mathbf{Y}_{\mathrm{i}}-\mathbf{Y}_{\text {mean }}\right)^{\mathbf{2}}$ \\
\hline 2006 & 133293 & 133293,00 & $-9450,67$ & 89315100,44 & 167002,28 & 24258,62 & 588480479,96 & 131207,47 & $-11536,20$ & $\overline{910,44}$ \\
\hline 2007 & 137595 & 136518,20 & $-6225,47$ & 38756435,22 & 163327,42 & 20583,75 & 423690753,50 & 134503,52 & $-8240,14$ & 67899 \\
\hline 2008 & 141996 & 139743,40 & $-3000,27$ & 9001600,07 & 159733,41 & 16989,75 & 28865 & 137799,58 & $-4944,09$ & 24443 \\
\hline 2009 & 146482 & 142968,60 & 224,93 & 50595,00 & 156218,50 & 13474,83 & 181571089,40 & 141095,64 & $-1648,03$ & 2715998,17 \\
\hline 2010 & 147677 & 146193,80 & 3450,13 & 11903420,02 & 152780,93 & 10037,26 & 100746605,04 & 144391,70 & 1648,03 & 2715998,17 \\
\hline 2011 & 149419 & 149419,00 & 6675,33 & 44560075,11 & 149419,00 & 6675,33 & 44560075,11 & 147687,75 & 4944,09 & 24443983,55 \\
\hline $\bar{\Sigma}$ & 856462 & & & 193587225,87 & & & 1627700537,24 & & & 255303828,19 \\
\hline \multicolumn{2}{|c|}{\begin{tabular}{|c|c|}
$Y_{\text {mean }}$ & 142743,67 \\
\end{tabular}} & & & & & & & & & \\
\hline \multicolumn{2}{|c|}{ Standar Deviasi } & & & 6222,33 & & & 18042,73 & & & 7145,68 \\
\hline
\end{tabular}


Berdasarkan Tabel 5 terlihat bahwa Metode Arithmatik memiliki standar deviasi yang lebih kecil dibandingkan dengan Metode Geometrik dan Metode Least Square. Artinya, peramalan jumlah penduduk Kota Palopo untuk tahun 2013 - 2017 akan menggunakan Metode Arithmatik. Lebih lanjut, perhatikan Grafik 2 berikut:

\section{Grafik 2. Jumlah Penduduk Kota Palopo Tahun 2006 - 2011}

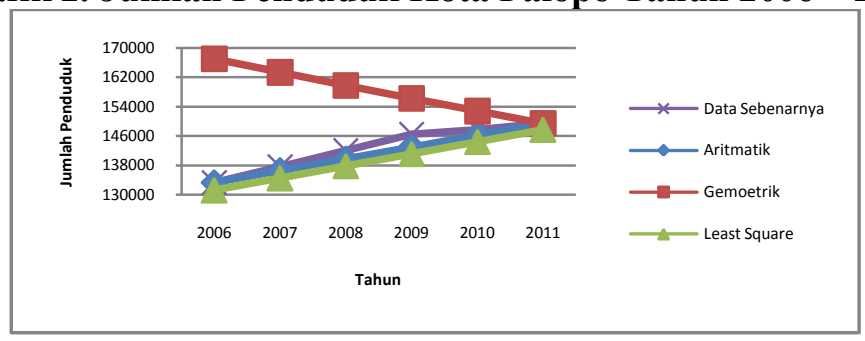

Metode Arithmatik adalah metode yang dipilih untuk menentukan jumlah penduduk Kota Palopo tahun 2013 - 2017. Untuk itu, melanjutkan perhitungan dengan menggunakan Persamaan (1), maka jumlah penduduk Kota Palopo untuk tahun 2013 - 2017 selengkapnya dapat dilihat pada Tabel 6 berikut:

Tabel 6. Jumlah Penduduk Kota Palopo Tahun 2013 - 2017 dengan Menggunakan Metode Arithmatik

\begin{tabular}{||c|c||}
\hline Tahun & Jumlah Penduduk Hasil Peramalan \\
\hline \hline 2013 & 155869 \\
\hline 2014 & 159094 \\
\hline 2015 & 162320 \\
\hline 2016 & 165545 \\
\hline 2017 & 168770 \\
\hline
\end{tabular}

Data jumlah penduduk Kota Palopo selengkapnya dapat dilihat pada Grafik 3 berikut: 
Grafik 3. Jumlah Penduduk Kota Palopo Tahun 2006 - 2017

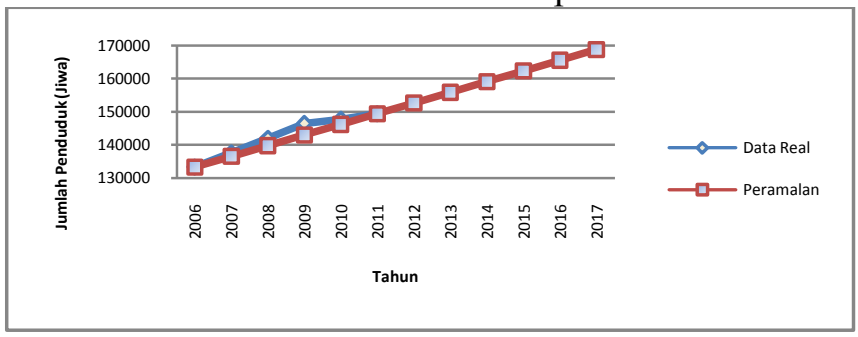

\section{Penutup}

Analisis regresi kuadrat terkecil telah diterapkan untuk meramalkan jumlah penduduk Kota Palopo tahun 2013 - 2017. Berikut kesimpulan dan saran yang dapat dilakukan untuk pengembangan peramalan jumlah penduduk Kota Palopo.

\section{A. Kesimpulan}

Dari analisis data yang telah dilakukan terhadap jumlah penduduk Kota Palopo tahun 2006 - 2011 dengan menggunakan analisis regresi kuadrat terkecil, maka dapat simpulkan sebagai berikut:

1. Dari ketiga metode yang digunakan yaitu Metode Arithmatik, Metode Geometrik, dan Metode Least Square, dalam menghitung kembali jumlah penduduk Kota Palopo tahun 2006 - 2011 terlihat bahwa Metode Arithmatik merupakan metode yang paling baik dengan standar deviasi yang lebih kecil dibandingkan dengan Metode Geometrik dan Metode Least Square. Untuk itu, Metode Arithmatik digunakan untuk meramalkan jumlah penduduk Kota Palopo tahun 2013 - 2017.

2. Berdasarkan Metode Arithmatik, jumlah penduduk kota Palopo untuk tahun 2013 sampai dengan 2017 berturut-turut sebesar 155869 Jiwa, 155869 Jiwa, 162320 Jiwa, 165545 Jiwa, dan 168770 , dengan rata-rata pertumbuhan penduduk sebesar 3225 Jiwa per tahun atau sekitar 2,25\%. 
B. Saran

Ada beberapa saran yang dimungkinkan untuk pengembangan tulisan ini diantaranya:

1. Peramalan jumlah penduduk Kota Palopo dapat lebih dibuat spesifik menurut wilayah kecamatan, kelurahan, dan atau jenis kelamin.

2. Peramalan jumlah penduduk dengan menggunakan Metode Arithmatik merupakan salah satu metode peramalan linear. Untuk itu, dapat kiranya dicari metode peramalan yang lain dalam bentuk nonlinear yang dapat memperkecil standar deviasi atau nilai error data.

\section{Daftar Pustaka}

Badan Pusat Statistik Kota Palopo., 2012, Palopo dalam Angka 2012, BPS: Palopo.

Boediono dan Wayan Koster., 2004, Teori dan Aplikasi: Statistika dan Probabilitas, PT Remaja Rosdakarya: Bandung.

Munir, Rinaldi., 2003, Metode Numerik, Penerbit Informatika: Bandung.

Rayer, Stefan dan Stanley K, Smith., 2008, An Evaluation of Subcounty Population Forecasts in Florida, Bureau of Economic and Business Research; University of Florida.

United Nations., 1952, Manual I: Methods of Estimating Total Population for Current Dates, United Nations Publications: Switzerland. 